\title{
A LINGUAGEM DO MOVIMENTO ESCOLA SEM PARTIDO: IDEOLOGIA, DOUTRINAÇÃO E NEUTRALIDADE
}

\author{
The Language of the Escola sem Partido Movement: \\ ideology, indoctrination and neutrality
}

Verônica Ventorini FERREIRA Universidade do Vale do Rio dos Sinos vferreira039@gmail.com https://orcid.org/0000-0002-0376-591X

Berenice CORSETTI Universidade do Vale do Rio dos Sinos bcorsetti@unisinos.br https://orcid.org/0000-0002-4457-8790

RESUMO: O presente artigo pretende apresentar a intencionalidade do Movimento Escola sem Partido (MESP) para a educação, a partir da análise sistemática dos conceitos adotados na linguagem do MESP. No foco da análise estão os conceitos de ideologia, doutrinação e neutralidade. $\mathrm{O}$ estudo apresentado é parte integrante de uma pesquisa mais abrangente que está fundamentada na hermenêutica filosófica (GADAMER, 2013) e na pedagogia histórico-crítica (SAVIANI, 2008), cujos pressupostos conduzem um processo metodológico de análise documental. Trabalhamos com os escritos das seções do site oficial do MESP. Um primeiro movimento metodológico corresponde ao mapeamento dos termos mais recorrentes em cada seção, para posterior aprofundamento dos significados historicamente atribuídos e suas implicações no atual contexto histórico. Entrevemos as perspectivas cientificista e tecnicista para a educação institucional, portanto, uma mudança no eixo ético-filosófico da educação brasileira.

PALAVRAS-CHAVE: Escola sem Partido; Doutrinação; Ideologia; Neutralidade.

\begin{abstract}
This article intends to present the intentionality of the Escola sem Partido Movement (MESP) for education, from the systematic analysis of the concepts adopted in the language of MESP. At the focus of the analysis are the concepts of ideology, indoctrination and neutrality. The study presented is part of a more comprehensive research that is based on philosophical hermeneutics and historical-critical pedagogy, whose assumptions lead to a methodological process of documentary analysis. We work with the writings of the sessions on the official MESP website. A first methodological movement corresponds to
\end{abstract}


the mapping of the most recurrent terms in each session, for further deepening of the historically attributed meanings and their implications in the current historical context. We observe the revival of scientism and technicist perspectives in the horizon of institutional education, therefore, a change in the ethical-philosophical axis of Brazilian education.

KEYWORDS: Escola sem Partido; Indoctrination; Ideology; Neutrality.

\section{ENTRE LINGUAGEM E INTENCIONALIDADE: UMA PROPOSTA DE COMPREENSÃO}

$\mathrm{O}$ artigo que segue tem por objetivo apresentar a intencionalidade do Movimento Escola sem Partido (MESP), a partir dos conceitos de ideologia, doutrinação e neutralidade. Ao examinarmos os conceitos de estrutura e sistema, a partir da pedagogia histórico crítica, desenvolvida por Dermeval Saviani, observamos que os termos utilizados pelo MESP, para fazer referência ao campo da educação, agem sistematicamente para a mudança das práticas pedagógicas. Isto é, não agem desordenadamente sobre as concepções de educação, mas agem intencionalmente difundindo percepções sobre a educação vigente, de tal forma a justificar seu intento de intervir na prática pedagógica.

De acordo com Saviani (1996) a estrutura se refere a um conjunto de elementos (econômicos, políticos, educacionais, sociais, etc.) que marcam a existência e as ações humanas, de tal forma, independente da consciência que temos sobre esses elementos eles nos marcam e influenciam nossas ações. Assim, a estrutura pode ser compreendida enquanto contexto que se impõe às diferentes existências humanas, o sistema faz referência a organicidade que o humano impõe ao seu contexto, portanto à realidade. $\mathrm{O}$ sistema é organizado a partir do momento em que o humano é capaz de perceber os elementos que o influenciam, tomando para si o controle sobre o sentido desses elementos. A sistematização dos elementos estruturantes da realidade resulta no que chamamos de sistema, como por exemplo, o sistema de educação.

Quando o MESP adentra a estrutura educacional apontando o problema da doutrinação e difundindo no imaginário coletivo o estereótipo do professor doutrinador, inicia-se um processo de desestabilização nos fundamentos do sistema educacional. De tal forma, a ideologia deixa de ser compreendida enquanto o conjunto de ideias orientadoras do sistema educacional, e a militância dos educadores é associada com práticas de 
doutrinação. Para compreender a intenção do MESP é preciso, também, compreender o que está sendo estruturado para o campo da educação, nosso esforço é estabelecer a compreensão a partir dos termos significativos na linguagem do movimento.

Com o apoio na hermenêutica filosófica, desenvolvida na obra de Hans-Georg Gadamer (2011), adentramos a estrutura da linguagem sobre a qual o MESP dota de sentido sua ação. Assim, justificamos a compreensão dos conceitos utilizados por um movimento que, diferentemente de outras iniciativas, não se auto justifica pela busca de melhoria dos índices que mensuram a qualidade da educação, mas pelo comportamento abusivo dos professores em relação aos estudantes. Então, verificamos que no campo da práxis pedagógica é no âmbito da ética docente, muito mais do que no âmbito da didática, que esse movimento encontra possibilidade para sustentação e intervenção no campo da educação. Logo, é na compreensão dos conceitos basilares da linguagem do MESP que poderemos observar sua intencionalidade frente ao campo da educação.

Consideramos como preceito teórico a relação entre a linguagem e seu contexto histórico-social. Para Gadamer (2011, p. 97), a linguagem "é a interpretação prévia pluriabrangente do mundo e por isso insubstituível. Antes de todo pensar crítico, filosófico-interventivo, o mundo sempre se nos apresenta numa interpretação feita pela linguagem". O que significa que a linguagem traduz e reforça a concepção que adquirimos do meio em que nos situamos. A compreensão dos termos utilizados pelo MESP é ponto de partida para situar o movimento dentro do campo político da educação, isto é, encontrar a dinâmica que permite a retomada de termos como neutralidade, ideologia e doutrinação em tempos que ensejam a valorização da subjetividade, do pensamento crítico e da reflexão.

É necessário, como afirma Gadamer (2011), ao se referir ao processo de compreensão, trazer para o terreno do estranhamento o que nos é apresentado como óbvio, logo, se o MESP nos apresenta como óbvio o sentido do termo ideologia, então devemos buscar o sentido do termo e motivo pelo qual está sendo utilizado. Esse movimento de busca permite uma compreensão de nossa própria condição histórica, moral e política, pois já não se trata de uma investigação histórico-conceitual, mas da compreensão acerca da intencionalidade do uso dos conceitos em nossa linguagem cotidiana.

$\mathrm{Na}$ escolha dos conceitos e da abordagem a ser utilizada, o primeiro momento da 
pesquisa foi destinado ao contato com o site do $\mathrm{MESP}^{1}$; por entender que as seções refletiam uma apresentação geral do Movimento, empreendemos o levantamento de termos significativos e tivemos retorno satisfatório para atender nosso objetivo. Observamos as recorrências de termos como doutrinação, ideologia e neutralidade. Por estarmos abordando uma dimensão ética da educação, buscamos, também, termos fundamentais para o campo: professor, aluno, estudante, ensino e aprendizagem.

Em cada seção, buscamos pelos termos supracitados, objetivando observar a representatividade de cada um e elencar aquele que daria início ao estudo. Descrever a recorrência e utilização dos termos guiou a reflexão sobre o ideário do movimento e o nível de importância que cada um adquire no todo do discurso. Nas seções do site, os termos escolhidos aparecem conforme a tabela abaixo.

Tabela 1: Recorrência de Termos nas Seções do Site do Movimento Escola sem Partido

\begin{tabular}{|c|c|c|c|c|c|c|}
\hline & Apresentação & $\begin{array}{c}\text { Quem } \\
\text { Somos }\end{array}$ & Objetivos & $\begin{array}{c}\text { Condições de } \\
\text { uso }\end{array}$ & FAQ & Total \\
\hline Doutrinação & 2 & 0 & 2 & 0 & 10 & 14 \\
\hline Neutralidade & 1 & 0 & 1 & 0 & 3 & 5 \\
\hline Professor & 2 & 1 & 3 & 1 & 21 & 28 \\
\hline Aluno & 0 & 2 & 2 & 0 & 17 & 21 \\
\hline Estudante & 1 & 2 & 3 & 1 & 12 & 19 \\
\hline Ensino & 1 & 2 & 3 & 1 & 8 & 15 \\
\hline Ideologia/Ideológico & 2 & 2 & 7 & 0 & 18 & 29 \\
\hline Aprendizagem & 0 & 0 & 0 & 0 & 0 & 0 \\
\hline
\end{tabular}

Fonte: Tabela elaborada pelas autoras.

A partir da tabela poderíamos estabelecer uma hierarquia de assuntos pertinentes, entretanto, iniciamos o estudo com o termo ideologia, pois as palavras suscitam um encadeamento forçado pelo próprio desenrolar de cada conceito. A relação entre ideologia, doutrinação e neutralidade é trabalhada de forma orgânica, ainda que os subtítulos assegurem um perfil sistemático ao conjunto do texto.

\footnotetext{
${ }^{1} \mathrm{O}$ site utilizado na pesquisa foi <https://www.escolasempartido.org/>. No ano de 2017, quando realizamos o levantamento dos conceitos, o site contava com as seções "apresentação", "quem somos", "objetivos", "condições de uso" e "FAQ". Acesso em: 20 jan. 2017.
} 


\section{OS CONCEITOS}

\section{A ideologia, razão de existência do MESP}

O termo ideologia foi elaborado por Destutt De Tracy, filósofo francês que viveu entre 1754 e 1836. No prefácio à Edição de 1804, da obra Elementos de Ideologia, afirma De Tracy: “A Ideologia é uma parte da Zoologia e é sobretudo no homem que essa parte é importante e merece ser aprofundada". Esclarece Löwy (1991) que o conceito de ideologia, elaborado por De Tracy, era mais uma teoria para superação da metafísica. Em sua concepção, a vida humana era regida por ideias que tinham sua origem no corpo humano, mais precisamente nas sensações, logo a ideologia foi pensada como uma ciência materialista das ideias. Entretanto, Napoleão acusava De Tracy de ser um especulador metafísico, pois percebia nas ideias do filósofo, mais alinhadas com o iluminismo e os ideais liberais, uma ameaça política. O sonho iluminista de superação do obscurantismo foi o terreno profícuo para a elaboração do termo, os dogmas sustentadores de uma sociedade tradicional começavam a sucumbir frente aos ideais da burguesia. Napoleão, ao deturpar os estudos de De Tracy, legou um sentido para o termo ideologia, isto é, uma especulação desvinculada da realidade.

A crítica promovida pela ideologia era, também, uma ideologia em dois sentidos diferentes (EAGLETON, 1997). Recorria ao empirismo de John Locke, e consequentemente à ideia de um indivíduo passivo e distinto, atendendo aos ideais da classe emergente, a burguesia. Por outro lado, apresentava a ciência e a razão como instâncias desinteressadas e opostas ao princípio da autoridade inquestionável que se apresentava na religião, na tradição e na política. Logo, a ciência, a partir da concepção empirista, serviu para encobrir a ascensão de um novo regime, onde o indivíduo poderia ser moldado pelo método educativo com bases científicas e a razão seria determinante da organização social. Uma ciência das ideias seria de extrema serventia aos ideais burgueses, não fosse o descrédito que seu autor sofrera pela influente figura de Napoleão que pretendia consolidar seu império.

Para De Tracy o ponto de partida para qualquer empreendimento, entre eles a organização social, seria a razão, jamais se poderia partir da religião ou da política. $\mathrm{O}$ ideólogo que Napoleão atacava, por terminar com as ilusões, entra em contradição a partir 
de seus estudos econômicos quando constata que a sociedade de classes era movida por interesses egoístas. A partir das considerações com o viés econômico, De Tracy reconhece que as paixões humanas e suas expressões materiais são o ponto em que as ciências encontram seu limite e sua necessidade de revisão.

O conceito de Ideologia será posteriormente abordado por Karl Marx (1818-1883) que lhe atribui o significado de velamento do real - a partir do pressuposto de que a ideia ofusca a realidade - e significado de configuração para a existência, isto é, a partir das ideias difundidas a existência é (de)formada.

Para Marx, claramente, ideologia é um conceito pejorativo, um conceito crítico que implica ilusão, ou se refere à consciência deformada da realidade que se dá através da ideologia dominante: as ideias das classes dominantes são as ideologias dominantes na sociedade. (LÖWY, 1991, p. 12).

A partir do pensamento de Marx, outros significados são atribuídos ao termo ideologia: para Lenin está associada as doutrinas das classes sociais; Karl Mannheim, a partir da distinção entre ideologia e utopia, estabelece o conceito de ideologia como "o conjunto das concepções, ideias, representações, teorias, que se orientam para a estabilização, ou legitimação, ou reprodução da ordem estabelecida" (LÖWY, 1991, p.13).

No século seguinte, com o fenômeno nazista ${ }^{2}$ (1933-1945), os debates sobre a temática da ideologia foram retomados, gerando contribuições como as da Escola de Frankfurt e da psicanálise, na medida em que esta pressupõe uma prática que desencobre as causas reais (veladas no sujeito) de atitudes patológicas (apresentadas no comportamento). Assim, é relevante registrar a recorrência de pressupostos psicanalíticos para abordar a ideologia, talvez como uma patologia social, para a qual as ciências hermenêuticas deveriam dar alguma resposta. Em outro sentido, temos nesse período uma espécie de escamoteação do termo por intelectuais representantes da direita e esquerda políticas. Podemos observar que os estudos, desde a elaboração de De Tracy até a psicanálise no período pós-guerra, ao se ocuparem com o conceito de ideologia, lançam

\footnotetext{
${ }^{2}$ Quando Hitler é nomeado chanceler do governo alemão em 1933, inicia a abertura do caminho para a consolidação do totalitarismo nazista, no mesmo ano o primeiro campo de concentração para presos políticos é instalado, a perseguição e a carnificina sistemática de judeus, negros, ciganos e tantos outros que representavam o diferente do "homem alemão" seguem até 1945.
} 
luz sobre uma dimensão que o puro saber prático não alcança, isto é, sobre as paixões humanas.

Tendo em vista o impacto dos movimentos totalitários sobre os estudos acerca do conceito de ideologia, é pertinente retomar as reflexões de Arendt (2012) a respeito do processo de difusão das ideologias nazista e socialista soviética no processo de ascensão do totalitarismo. A autora destaca o uso da propaganda como um meio eficiente de difusão e aceitação da ideologia pelo público externo aos movimentos totalitários, de uma vez que, a propaganda traduz como algo aceitável as ideias dos movimentos totalitários, tais como a do racismo e do socialismo.Logo, as ideias são utilizadas como princípios para explicar o movimento da natureza, que produz a superioridade da raça no racismo e a dialética como determinação da história, para ser a verdade fundante e justificante da realidade, não admitindo premissas contraditórias ou a experiência com a realidade.

O perigo de trocar a necessária insegurança do pensamento filosófico pela explicação total da ideologia e por sua Weltanschauung ${ }^{3}$ não é tanto o risco de ser iludido por alguma suposição geralmente vulgar e sempre destituída de crítica quanto o de pensar pela camisa de força da lógica, que pode subjugar o homem quase tão violentamente quanto uma força externa. (ARENDT, 2012, p. 626).

Percebemos que o discurso ideológico totalitário busca alguma fundamentação aparentemente científica, ou mesmo algum representante empírico de sua ideia geral, e passa a fazer dessa fundamentação uma justificativa para o que há de degradante em seus objetivos. De acordo com Gadamer (2013), no acontecimento da linguagem estão presentes aquilo que persiste e a mudança das coisas, bem como, a contribuição para o estabelecimento de nossas ações frente ao mundo. Consideramos que a dinâmica de difusão das ideologias totalitárias encontra na linguagem um ponto de sustentação, vide a necessidade de consolidar a ideia de raça como premissa inquestionável, ponto de partida, para as ações nazistas.

\footnotetext{
${ }^{3} \mathrm{O}$ termo Weltanschauung é traduzido por cosmovisão, visão de mundo.
} 


\title{
Ideologia: da tradição para o contexto brasileiro
}

Observamos como surge o conceito de ideologia e como a palavra representa a situação concreta do uso das ideias, para obtenção de interesses divergentes das próprias ideias. Cabe agora buscar o conceito no discurso do MESP.

\begin{abstract}
Numa sociedade livre, as escolas deveriam funcionar como centros de produção e difusão do conhecimento, abertos às mais diversas perspectivas de investigação e capazes, por isso, de refletir, com neutralidade e equilíbrio, os infinitos matizes da realidade. No Brasil, entretanto, a despeito da mais ampla liberdade, boa parte das escolas, tanto públicas, como particulares, lamentavelmente já não cumpre esse papel. Vítimas do assédio de grupos e correntes políticas e ideológicas com pretensões claramente hegemônicas, essas escolas se transformaram em meras caixas de ressonância das doutrinas e das agendas desses grupos e dessas correntes. A imensa maioria dos educadores e das autoridades, quando não promove ou apóia a doutrinação, ignora culposamente o problema ou se recusa a admiti-lo, por cumplicidade, conveniência ou covardia. O EscolasemPartido.org -- único site em língua portuguesa inteiramente dedicado ao problema da instrumentalização do ensino para fins políticos e ideológicos -- foi criado para mostrar que esse problema não apenas existe, como está presente, de algum modo, em praticamente todas as instituições de ensino do país. (ESCOLA SEM PARTIDO, 2014a).
\end{abstract}

O início do excerto versa sobre as funções da escola, mas afirma a existência e presença, "em praticamente todas as instituições do país", do problema da “instrumentalização do ensino para fins políticos e ideológicos”. Considerando que, se ideologia for um conjunto de ideias e a finalidade política for a participação dos cidadãos na coisa pública (rés publica), então nada mais teremos para dizer além de que: "sim, as escolas possuem finalidade política e ideológica!", isto é, temos um conjunto de ideias que nos orientam e encontram sua realização na formação de cidadãos que trabalham, conforme expresso na LDBN no 9.394/1996, Art. 2a. Formar "cidadãos que trabalham" é um objetivo ideológico, na medida em que é fruto dos ideários liberais que permeiam a constituição da escola brasileira, bem como, é um objetivo político, pois está vinculado à sustentação do estado democrático. Assim, a instituição escolar traduz em suas ações uma perspectiva ideológica e política que vincula o humano ao exercício da cidadania e ao mundo do trabalho. Se o objetivo fosse formar "humanos que trabalham" o viés 
ideológico e político seria diferente, teríamos uma instituição cujas ações seriam responsáveis por inserir o humano no mundo do trabalho, sem preocupação com o exercício da cidadania.

Entretanto, a ideologia pensada pelo movimento é um conjunto de ideias que se sobrepõe a outros conjuntos de ideias, e a partir da afirmativa de que existem práticas ideológicas é que o movimento justifica sua existência. Percebemos aqui uma similaridade com as dinâmicas discursivas apreendidas nas análises de Arendt acerca dos movimentos totalitários, logo, em um primeiro momento, o movimento busca comprovar que a existência de ideologia é um problema no campo da educação.

\begin{abstract}
EscolasemPartido.org foi criado para dar visibilidade a um problema gravíssimo que atinge a imensa maioria das escolas e universidades brasileiras: a instrumentalização do ensino para fins políticos, ideológicos e partidários. E o modo de fazê-lo é divulgar o testemunho das vítimas, ou seja, dos próprios alunos. (ESCOLA SEM PARTIDO, 2014c).
\end{abstract}

Os termos que o MESP utiliza para qualificar o "problema gravíssimo" possuem sentido retórico, isto é, preenchem a argumentação favorável ao movimento, mas se esvaziam tão logo há a percepção de que o próprio movimento possui uma ideologia (um conjunto de ideias), é político (legitima e busca legalizar preceitos de conduta para os docentes, se convertendo em uma questão de disputa política) e, também, é partidário (possui apoio de partidos políticos). A afirmativa de que as escolas foram instrumentalizadas para fins políticos é um recurso propagandístico - tão torpe quanto o uso do termo "raça" na ideologia nazista, como vimos anteriormente - para agregar público. Esse argumento convence aqueles que desconhecem as origens da instituição escolar como um meio de refinamento da política. Isto é, na antiguidade, com o estabelecimento da pólis grega, que a educação do cidadão se torna motivo de reflexão, pois este deve se envolver no debate político, portanto, nos rumos da coisa pública. De lá para cá, várias foram as ideologias que permearam a trajetória da educação escolar em diferentes momentos e partes do globo. Quando o MESP reivindica a desideologização da instituição escolar, não pretende uma escola sem ideologias, pretende uma escola cuja única ideologia é a que o movimento sustenta. 
A universidade, por ser a principal instituição formadora de professores ${ }^{4}$,é apresentada como o grande centro de doutrinação. No entanto, é o desenvolvimento da racionalidade crítica, fundamental para o avanço das ciências, que é atacado quando o MESP faz referência às universidades. Mas, ainda que o movimento aponte para a formação dos professores, pretende que a contenção do problema da doutrinação se dê na educação básica, com a supervisão da escola e a responsabilização dos professores.

Lutamos: pela descontaminação e desmonopolização política e ideológica das escolas. Sabemos que o conhecimento é vulnerável à contaminação ideológica e que o ideal da perfeita neutralidade e objetividade é inatingível. Mas sabemos também que, como todo ideal, ele pode ser perseguido. Por isso, sustentamos que todo professor tem o dever ético e profissional de se esforçar para alcançar esse ideal. Paralelamente, é fundamental que as escolas adotem medidas concretas para assegurar a diversidade de perspectivas ideológicas nos seus respectivos corpos docentes. Afinal, em matéria de conhecimento, o pior dos mundos é o do monopólio ideológico. Pelo respeito à integridade intelectual e moral dos estudantes. (ESCOLA SEM PARTIDO, 2014c).

A ideia-solução para o problema da ideologia nas escolas é a "busca pela neutralidade e objetividade" na abordagem dos conteúdos escolares. O MESP, como é evidente no excerto, determinou um dever ético para os professores e incita as equipes que direcionam as escolas, os estudantes e a sociedade a promover ações para garantir esse ideal. Logo, sob a premissa da "integridade intelectual e moral dos estudantes" a possibilidade de reflexão, sobre os conteúdos abordados em sala de aula, é extirpada enquanto cedendo lugar ao ideal da neutralidade como único possível. Logo, o arcabouço de ideias, da forma como estão dispostas pelo MESP, confunde a consciência histórica e política acerca das funções da escola básica, bem como a relevância dos estudos acadêmicos.

Se considerarmos a historicidade da educação brasileira observaremos que as ideias básicas que circulavam como fio condutor da formação humana foram o cerne do debate que envolvia a escola tradicional e o desenvolvimento da doutrina liberal para a

\footnotetext{
${ }^{4}$ Nos referimos aqui como a principal instituição pois consideramos que o Curso Normal ainda é uma modalidade de ensino que promove a formação de professores para a educação básica, mas o MESP não o cita em momento algum.
} 
escola pública, via Escola Nova ${ }^{5}$. Isso significa que o debate sobre as ideias que influenciam a educação não é novidade, mas sim a acusação de que os professores fazem doutrinação ou ideologização em sala de aula como um dado comprovado e inquestionável. Se observarmos o âmbito das reformas políticas, para a educação, perceberemos que elas acontecem a cada troca de governo, abrindo margem para condicionantes político-partidários aos processos educativos. Assim, se promove, a partir da esfera mais ampla do poder público, as ideias que direcionam a educação, a saúde, a segurança, etc.

No momento em que deixamos falar a tradição histórica (GADAMER, 2013), entendemos que a educação é um terreno de coexistência de tendências pedagógicas diferentes, por vezes, divergentes, e de disputas políticas acirradas. A partir desse momento, torna-se possível compreender que o MESP adentra esse terreno de disputas, ideológicas e políticas, dotando o tema das ideologias de uma novidade que ele não possui. Entretanto, não o faz de modo desinteressado, mas atuando na desvalorização da profissão docente e na regulação do acesso ao conhecimento, principalmente no campo das humanidades.

O MESP utiliza o termo ideologia no sentido de um artifício lógico argumentativo para justificar suas intervenções no campo da educação, isto é, a função do termo ideologia é abarcar tudo o que não pode ser enquadrado no padrão ideológico do MESP e que, por tanto, passa a ser considerado danoso à educação. De tal forma, a única realidade educacional aceitável é aquela idealizada pelo MESP, o que não atende a idealização ganha o rótulo de ideologia, entendida enquanto ofuscamento do real.

Observando os usos do termo ideologia, pelo movimento, podemos constatar a criação de um problema no campo educacional brasileiro, isto é, o MESP fez de um aspecto constitutivo da educação, a presença de ideologia, entendida enquanto conjunto de ideias que sustentam o campo, um entrave para a promoção da educação. A solução encontrada para o problema recai na busca incessante por neutralidade e objetividade

\footnotetext{
${ }^{5}$ A Escola Nova foi, no Brasil, o movimento de contraposição a uma perspectiva conservadora e dualista de educação, promotora dos ideais liberais para a educação. Buscava ampliar e promover a educação pública, leiga, de qualidade e gratuita para todos. Diferentemente de outros países, no Brasil essa perspectiva foi adotada sistematicamente, a partir da década de 1930, nas Diretorias de Instrução Pública, vinculadas ao Ministério de Educação e Saúde, especialmente no que tange às reformas educacionais relacionadas ao ensino primário. Anísio Teixeira, Fernando de Azevedo e Lourenço Filho são expoentes da difusão dos ideais da Escola Nova no país.
} 
como padrão ético-pedagógico, contra as práticas pedagógicas doutrinárias.

\title{
Doutrinação: a ética pedagógica em foco
}

A prática pedagógica é constituída por inúmeros aspectos, mas para compreendermos o que se passa com a questão da doutrinação, parece-nos importante o desdobramento de dois aspectos filosóficos no campo da educação, isto é, a ética docente e os objetivos da prática educativa e da escolarização.

$\mathrm{O}$ encontro entre os seres docente e discente acontece sobre um fundamento ético pedagógico, de tal forma que quando o MESP delineia a figura docente e, com isso, cria uma ideia de como são os discentes, também estabelece a ética pedagógica que deveria vigorar. No excerto, abaixo, o encontro entre docentes e discentes está pautado em uma ética pedagógica que ignora qualquer possibilidade de reflexão e ação crítica por parte dos estudantes e, além disso, apresenta a figura docente como dominante sobre a mentalidade e as ações dos estudantes.

\begin{abstract}
A doutrinação é um problema grave na educação brasileira? Por quê? Sim, por três razões. Primeiro, porque consiste numa forma de cerceamento da liberdade de aprender do estudante, já que, numa de suas vertentes, essa liberdade - que é garantida expressamente pela Constituição Federal - compreende o direito do estudante de não ser doutrinado por seus professores. Trata-se, portanto, da violação a um direito fundamental. Segundo, porque as principais vítimas dessa prática são jovens inexperientes e imaturos, incapazes de reagir, intelectual e emocionalmente, a um professor que esteja determinado a "fazer a cabeça" dos alunos. E, terceiro, devido à extensão do fenômeno: segundo pesquisa realizada pelo Instituto Sensus (ver quadro abaixo), a imensa maioria dos professores (78\%) acredita que a principal missão da escola é "despertar a consciência crítica dos alunos". (ESCOLA SEM PARTIDO, 2014e).
\end{abstract}

De tal forma que o estudante é um ser passivo e indefeso, enquanto o docente é ativo e direcionador do processo, observamos aqui um pressuposto ético-pedagógico alinhado ao ideal liberal ${ }^{6}$. Como contraponto, boa contribuição foi legada pela perspectiva

\footnotetext{
${ }^{6}$ A doutrina liberal defende o predomínio da liberdade e dos interesses individuais, bem como, estabelece um modelo de organização social baseado na propriedade privada dos meios de produção. A pedagogia liberal representa essa sociedade que promova a adequação do indivíduo ao seu papel social. (LUCKESI, 2011).
} 
crítica, que não vê no estudante a tábula rasa como previa o pai do liberalismo, John Locke, mas um ser que traz consigo experiências do mundo que vivencia, a partir das quais podemos iniciar o processo de desenvolvimento do conhecimento. O viés crítico no campo da educação legou às pedagogias progressistas, como exemplo temos a oposição de Freire (1987) às práticas educativas que doutrinam os educandos, mantendo-os ingênuos em relação ao lugar que ocupam no mundo; bem como, as considerações de Saviani (2008) acerca da função da escola enquanto instituição que proporciona o acesso aos saberes que podem levar o educando ao conhecimento elaborado, elevando-o além de sua condição natural.

Se considerarmos que a capacidade de raciocinar, por si mesmo, sobre o mundo que nos circunda conectando os conhecimentos escolares aos fenômenos cotidianos,é o raciocinar criticamente. Isto é, ter a capacidade de avaliar por si o que se apresenta, recorrendo ao conjunto de conhecimentos que adquirimos ao longo de nossas experiências e, também, ao longo de nossa escolarização. Então, a afirmativa de que os professores buscam despertar a consciência crítica só é um problema quando o objetivo da educação escolar não perpassa a emancipação intelectual dos estudantes.

O MESP (2014e), afirma que a doutrinação político-ideológica é promovida em sala de aula "de forma sistemática e organizada, com apoio teórico (Gramsci, Althusser, Freire, Saviani etc.)", no entanto, as teorias críticas não admitem que o professor reforce ou promova a passividade do estudante no espaço da sala de aula, isto é, há incompatibilidade entre a prática pedagógica de viés crítico e estudantes passíveis de doutrinação. Além dessa contradição, no discurso do MESP, fica evidente o esforço para promover, através do ataque aos teóricos críticos, uma educação unilateral, pautada em pressupostos pedagógicos liberais. Isso significa, mais do que a idealização de um sistema educacional, a disseminação do terror da doutrinação e a instauração de uma crise nos fundamentos da educação brasileira - cujos pressupostos consolidam a pluralidade de ideias ao admitir nuances liberais e progressistas coexistindo nas escolas - evidenciando o objetivo, do movimento, de alargar um caminho antidemocrático, que nunca foi extinto, na área da educação.

Os estudantes e seus pais podem e devem reclamar; os responsáveis pelas escolas podem e devem exigir uma postura mais ética por parte dos 
professores. Mas se o professor estiver realmente determinado a fazer a cabeça dos alunos, será muito difícil impedi-lo, tendo em vista a circunstância de os abusos ocorrerem no recinto fechado das salas de aula. Por isso acreditamos que a única forma de combater a doutrinação é conscientizar diretamente os alunos (e, por tabela, também os professores) dos direitos compreendidos na sua liberdade de aprender. (ESCOLA SEM PARTIDO, 2014e).

A sala de aula é um espaço público, do qual não se pode impedir a entrada ou saída dos estudantes, principalmente se considerarmos o percurso das pedagogias progressistas, para as quais o caminho para a educação deve ser permeado pelo diálogo, pela escuta atenta do diferente, pelo respeito entre alunos e professores, bem como, pela garantia de acesso ao saber sistematizado (SAVIANI, 2008). Essas características das pedagogias progressistas são posturas éticas, pertencem ao âmbito do político no exercício da profissão docente, isto é, são a mediação pela qual o professor cumpre seu papel social, de tal modo que assume um posicionamento promotor da humanização e da cidadania ou da reprodução, ao ignorar seu papel social. A este âmbito, político, da educação, podemos afirmar que pertence o "tripé formado pelo domínio do saber teórico, pela apropriação da habilitação técnica e pela sensibilidade ao caráter político das relações sociais" (SEVERINO, 2005, p. 151), todos eles entrelaçados pelo compromisso docente com o futuro dos cidadãos que estão em formação.

Quando o movimento propõe conscientizar os estudantes e prover meios de proteção, contra possíveis professores, doutrinadores promove uma ação política que extrapola a relação docente-discente. Isso porque o professor, anteriormente compreendido como profissional comprometido com a mediação entre o estudante e o conhecimento, promotor, portanto, de um sistema social mais igualitário no que toca ao aparato cultural, passa a ser apresentado como inimigo do conhecimento e do estudante, necessitando de supervisão constante.

Com esse objetivo, o ESP elaborou o Cartaz com os Deveres do Professor. Defendemos que um cartaz como este seja afixado em todas as salas de aula das últimas séries do ensino fundamental, do ensino médio e dos cursinhos pré-vestibulares; e também nas salas dos professores. Além de conscientizar os estudantes dos seus direitos - o que é uma questão de estrita cidadania -; e de dar-lhes os meios de que eles necessitam para se defender do professor militante, esse cartaz expressa um apelo à consciência moral do professor, recordando-o de 
que ao lado da sua liberdade de ensinar está a liberdade de aprender dos alunos. (ESCOLA SEM PARTIDO, 2014e).

Logo, ao lado do terror da doutrinação, há o fantasma do professor militante, uma nova categoria para designar os suspeitos da ação de doutrinar. É perceptível que o professor militante, é aquele que milita por alguma causa, e pode significar a militância como o bom exercício de sua profissão, que deve legar ao aluno as ferramentas básicas (leitura, escrita, linguagem matemática, literatura, arte etc.) para compreensão do mundo, bem como pode empreender a militância aderindo a organizações de origens diversas, sem que isso, necessariamente, se converta para a área profissional. Dizer que um militante é necessariamente doutrinador significa incorrer em erro de compreensão acerca do que designa cada palavra. Além de utilizar esse erro categorial como premissa para deturpar a imagem de professores que militam em causas da educação, isto é, em benefício do futuro cidadão, da instituição escolar pública e de qualidade. Mas para o movimento, a militância, seja qual for, se converte em prática doutrinária que pode e deve ser contida, para tanto, basta que os estudantes frequentem as aulas para supervisionar seus professores, abdicando de seu direito de aprender.

O efeito, dessa lógica de deturpação da imagem do professor, sobre o estudante é o fechamento para o processo da aprendizagem. Um exemplo claro são as crianças em fase de alfabetização, para quem a figura do professor foi pintada praticamente como a de um carrasco, isso impede a entrega da criança ao processo de alfabetização. A dificuldade não está na criança ou no professor, mas na representação que foi criada sobre um professor. Os estudantes que frequentam a escola acreditando que no lugar de um professor há um doutrinador, irão resistir ao desenvolvimento do conhecimento escolar.

Logo, o que está em questão para o MESP é o aspecto ético-político presente na educação, perceberemos a tentativa de esmaecimento e dissolução desse aspecto (algo que consideramos impossível), na criação de um imaginário sobre o docente, bem como na defesa da neutralidade e objetividade promovida pelo movimento. Para melhor compreender como se desenvolve a noção de neutralidade retomaremos brevemente sua origem e as consequências de sua aplicação nas ciências humanas. 


\section{Neutralidade: um efeito da objetificação}

O tema da neutralidade aparece subentendido, em 1624, na defesa de Galileu Galilei (2005) ao sistema heliocêntrico, na medida em que busca defender o conhecimento demonstrável de modo claro contra os pressupostos da física defendidos por via de argumentos de autoridade. Já no século XIX, é no pensamento positivista, como exigência do fazer científico, pautado no método, na distinção do fenômeno, na clareza dos objetivos e na desvinculação com valores morais, que a neutralidade adquire centralidade. No âmbito da sociologia, Durkheim ressalta o caráter conservador do positivismo, que ao naturalizar os processos sociais ignora a possibilidade de mudança social pela ação humana.

Entretanto, a perspectiva positivista não pode ser considerada como superada quando estamos às voltas com um movimento que pretende aplicá-la de forma mais contundente à educação. Isto é, a neutralidade já se apresenta no campo educacional, de modo sutil, através do modelo gerencial que é refratário ao debate político que acontece no estabelecimento dos processos pelos quais os resultados são obtidos.

Ao promover o ideal da neutralidade no campo educacional o MESP acaba por transferir, para o campo da relação docente-discente, pressupostos como a objetividade, relacionada ao debate das ciências e a responsabilização, até então presente no campo da avaliação da aprendizagem, em que se estabelecem os rankings das melhores escolas.

A relação entre neutralidade e objetividade fica pode ser entendida com o excerto abaixo:

A justificativa-padrão utilizada pelos promotores da doutrinação ideológica nas escolas é a de que "não existe imparcialidade", já que "todo mundo tem um lado". Para os professores e autores militantes, isto resolve o problema, pois, se não existe neutralidade, cada um que cuide de "puxar a brasa para a sua sardinha". A dose de má-fé embutida nesse raciocínio é extraordinária. $\mathrm{O}$ fato de o conhecimento ser vulnerável à distorção ideológica - o que é uma realidade inegável, sobretudo no campo das ciências sociais - deveria servir de alerta para que os educadores adotassem as precauções metodológicas necessárias para reduzir a distorção. Em vez disso, a militância utiliza esse fato como salvo-conduto para a doutrinação. A perfeita objetividade científica pode ser impossível; mas perseguir o ideal da objetividade científica é não apenas possível, como moralmente obrigatório para um professor. (ESCOLA SEM PARTIDO, 2014e). 
Nesse excerto o movimento utiliza os termos imparcialidade, neutralidade e objetividade para fazer referência aos ideais que deveriam pautar as ações pedagógicas. Consideramos que esses termos possuem o mesmo sentido, entretanto, é necessário reconhecer que a neutralidade está fundamentada na objetividade. Esta, por sua vez, está atrelada a noção de verdade, tal como concebida pelo ideal moderno de ciência. Logo, verdadeiro é o que reduz em um conceito traços objetivos de um ser, de um fenômeno ou de um objeto, negando as possibilidades de expressão da experiência subjetiva. No entanto, "Experimentamos constantemente formas de comunicação para aquilo que não é objetificável, formas que nos são proporcionadas pela linguagem, inclusive pela dos poetas." (GADAMER, 2011 p. 63).

$\mathrm{O}$ docente que assume uma ética pautada na objetividade científica recusa a humanidade dos discentes, convertendo-os em objetos que devem ser moldados por uma abordagem didática pensada anteriormente ao encontro com os estudantes. Isso significa um recuo no campo pedagógico, tendo em vista que, é apenas no encontro entre o eu (cientista/docente) e o outro (objeto/discente) que se apresenta a possibilidade da abordagem adequada para mediar a relação entre o conhecimento e as experiências que o estudante possui.

Isso não significa a negação do conhecimento objetivo, apenas que este não é o único existente, nem mesmo pode ser considerado o único que circula em sala de aula. $\mathrm{O}$ conhecimento objetivo, afirma Saviani (2008) é o que justifica a existência da escola, tal conhecimento se caracteriza por tudo aquilo que se tornou clássico e que precisa ser assimilado por nossos jovens para que consigam sobreviver e viver em sociedade. Tal conhecimento é designado por currículo escolar, no entanto, se o currículo não for desenvolvido com uma abordagem que considera as subjetividades, diferente do que se experimenta na pedagogia liberal tradicional, ele será sempre uma lista de conteúdos, para professores e estudantes. Isto é, a assimilação, a significação e a aplicação no contexto subjetivo é o que sustenta a existência da relação docente-discente, assim objetividade e subjetividade se encontram no fazer pedagógico em uma dinâmica harmônica. $O$ movimento promove, com seu ideal de neutralidade, a supressão dessa dinâmica, em favor dos aspectos objetivos sobre os subjetivos.

Afirmamos que, seja por defender ideologias que convertem humanos em meios, 
e não em fins em si mesmos, ou por ignorância das peculiaridades da profissão docente, o MESP promove o ataque à formação para a cidadania quando advoga em favor do perfil de neutralidade para a docência. $\mathrm{O}$ conceito de neutralidade expõe o que deve significar o atuação do professor, qual seja, a negação de si e dos estudantes, enquanto seres que possuem conhecimentos diversos, e que podem reconhecer, ampliar e aplicar seus conhecimentos de modo significativo, principalmente quando o encontro entre os seres pode acontecer de forma amistosa e acolhedora.

\section{O SENTIDO DA LINGUAGEM E A ESTRUTURAÇÃO DA INTENCIONALIDADE}

A partir das considerações com os termos ideologia, doutrinação e neutralidade observamos a presença permanente de um ideal para a educação, que se pretende defensor da integridade intelectual, orientador das ações pedagógicas e definidor dos currículos escolares. O MESP, ao retratar o que acredita ser a doutrinação e a existência de ideologia unilateral no campo pedagógico, defende que a integridade intelectual dos estudantes só é possível com a desconfiança e com a adesão a ideários que prezam pela abstenção da subjetividade.

Quando promove ações para motivar os estudantes a supervisionar e denunciar as ações pedagógicas que não aderem ao modelo do movimento, promove o terrorismo entre docentes. Ainda, quando acusa os professores de doutrinação são os estudantes e responsáveis que se aterrorizam com a possibilidade de uma educação que visa a estagnação do pensamento autônomo. Se o próprio terror, como afirma Gadamer (2011, p.55) "repousa no fato de que os aterrorizados aterrorizam a si mesmos", então podemos afirmar que o MESP promove o terrorismo entre professores e estudantes.

Ao estipular a objetividade como padrão faz do eixo central dos currículos escolares, qual seja, o conhecimento historicamente acumulado e sistematizado, o único aceitável. Logo, se assistimos a todo momento as críticas a um currículo ampliado que, neutraliza o processo de democratização do conhecimento historicamente acumulado, de acordo com Saviani (2008), pois planifica o conhecimento e as outras atividades escolares. Também assistimos, com o MESP, uma tentativa de esvaziamento do currículo, na medida em que propaga como conhecimento apenas aquele referente ao que é objetivável. 
Deturpando as relações de diálogo que, com seus aspectos subjetivos, contribuem para o processo de aquisição do conhecimento objetivo, bem como, para a formação do sujeito. Logo, a atividade escolar é mais do que a "transmissão-assimilação de conhecimentos", bem como, não é apenas isso, mas se realiza nesse diálogo incessante entre os conhecimentos curriculares e o que está além destes.

A linguagem utilizada pelo MESP desvela seu alinhamento com os ideários que fundamentam as pedagogias liberais de cunho tradicional, ao mesmo tempo em que, desfigura a imagem dos professores, que na pedagogia tradicional é figura central enquanto desempenha o papel de repositório do conhecimento. Por outro lado, podemos considerar que o movimento se insere no âmbito da avaliação das práticas pedagógicas, de uma vez que dissemina a ideia de que todo estudante é um supervisor de seus professores. Nesse sentido o movimento desloca a avaliação do desempenho pelos resultados escolares, para avaliar o desempenho dos professores por sua postura ética.

Logo, o MESP atua na estrutura da educação, isto é, através de aspectos que vão se modificando nos contextos escolares, o imaginário coletivo sobre os professores exerce um poder sobre o professor que é impelido a alterar sua conduta, de tal forma que, infelizmente, legitima a ideologia que o movimento promove. Bem como, a ideia de que alguns conteúdos são ideológicos surge nas conversas entre professores e se propaga até a definição do currículo para o ano letivo, em que escolhas coletivas são feitas. Dessa forma, as práticas pedagógicas vão se entretecendo aos preceitos do MESP, modificando o fundamento ético da estrutura educacional.

Para além disso, observamos que o MESP traz para a superfície dos assuntos políticos-educacionais, questões por vezes percebidas como menos urgentes. Essas questões se referem principalmente ao campo da filosofia da educação, que aborda, entre outras, as temáticas da ética pedagógica e das tendências para a educação, a partir de seus fundamentos teóricos, sociais e políticos. Quando esses assuntos são trazidos de forma tão dramática para o debate público, no sentido de que a sociedade toda é convidada a formar uma opinião, tornam-se conscientes passando a interferir, então, no sistema educacional. Isto é, as ideias do movimento já não agem no nível do imaginário coletivo, mas são levadas ao âmbito político, por seus representantes, para que possam ganhar o estatuto de lei e exercer, com toda sua força, o condicionamento das práticas pedagógicas e dos 
currículos escolares.

Assim, podemos afirmar, a partir das considerações acerca de estrutura e sistema, que a intencionalidade do MESP é converter seus pressupostos para a educação em prática consolidada entre professores, seja pelo domínio do inconsciente coletivo ou pela imposição da lei. Os pressupostos, conforme as análises dos termos, agem no sentido de censura das subjetividades, bem como, na supressão do aspecto ético-político que permeia a educação e no estreitamento dos currículos escolares, pela dilapidação do que é transversal ao conhecimento objetivo. Logo, o movimento intenciona promover o estreitamento dos efeitos de uma educação pautada por princípios democráticos, em favor de uma educação objetiva em que conteúdos, professores e estudantes são apenas frutos do pensamento unilateral, cujos efeitos tendem para o desligamento entre a educação e a cidadania.

Tal desligamento apenas reforçaria o caráter tecnicista da educação, em que seria preciso controle dos processos para repasse de informações, a experiência de uma escola com perfil tecnicista a realidade brasileira já vivenciou. A escola tecnicista foi implementada através das Leis $n^{\circ} 5.540 / 1968$ e $n^{\circ} 5.692 / 1971$, em que o ensino superior e de $1^{\circ}$ e $2^{\circ}$ graus são reorganizados com ideário contrário ao da Escola Nova. Como afirma Luckesi (2011), essas eram as políticas oficiais, o que não significa que os professores tenham aceito o ideário conservador em que se sustentavam as reformas para a educação tecnicista. Agora, o MESP, retoma esse ideário, mas não o pretende na organização do sistema educacional, o pretende, como observamos, na relação docente-discente.

\section{CONSIDERAÇÕES FINAIS}

A tentativa de mudança estrutural empreendida pelo MESP deixa um alerta para o modo como os professores utilizam seu espaço público de atuação, sua linguagem e suas técnicas para promover o acesso ao conhecimento. O alerta não segue o sentido de uma adequação covarde aos princípios do MESP, já expomos como essa postura legitima o ideário unilateral.O alerta fica no sentido de que é cada vez mais necessária a coragem de promover uma educação emancipadora, capaz de fazer com que nossos estudantes percebam que os conteúdos escolares, da física à filosofia, estão encarnados na vida cotidiana de seu contexto existencial. 
Um tal alerta não promove nenhuma revolução novidadeira para a educação, mas certamente recupera o sentido de nossa atuação docente no horizonte político, pois, a resistência ao pensamento unilateral, ao obscurantismo da explanação objetiva do conhecimento escolar, só se faz quando os professores atuam de tal maneira que esse conhecimento, tão estranho para o estudante, ganhe sentido para a sua existência. E porque a vida humana necessita, também, do que não é tão objetivo, é que a escolarização que oferece o belo, a reflexão, o debate, a oportunidade de conhecer a si enquanto se conhece a história e de ver a si enquanto se estuda sociologia, é humanizadora.

A educação que humaniza desacomoda, porque dá a docentes e discentes o direito de saber que toda construção humana, assim como foi inventada, está passível de ser modificada. Nesse sentido, de um artefato, como uma caneta, até a grande estrutura da sociedade, há o elemento humano fundamental da criatividade, que uma educação estreita, como pretende o MESP, é incapaz de promover.

Na história da educação brasileira os movimentos por uma educação capaz de promover a cidadania e a humanização se deram no tensionamento entre posicionamentos conservadores e progressistas. O MESP, em nosso contexto histórico, representa a emersão de posicionamentos conservadores para o campo da educação, logo, o tensionamento se faz presente de forma mais incisiva, já que possui nome, agrega pessoas, dissemina o terror entre professores e estudantes, forma opiniões e consolida políticas para a educação.

Consideramos que no nosso momento essa personificação do conservadorismo na educação, o MESP, deve nos impelir a ter clara a relação entre ética, política e educação, a fim de perfazer um caminho pedagógico comprometido com o futuro de uma democracia experienciada por todos. Mais do que ter claro o papel político da educação entre os pares, é necessária a exposição de que a experiência democrática inicia na escola, enraíza no sujeito e gera frutos na sociedade, e que o conservadorismo é o impedimento para colher os frutos. Por isso, para os professores o MESP será sempre uma contradição, que na boa acepção dialética, apenas irá nos mover para a consciência de nossa função política, e jamais para a consolidação do ideário unilateral como uma opção de caminho pedagógico. Afinal, também durante a ditadura militar brasileira, foi a clara consciência política dos professores que não permitiu a consolidação de ideologia unilateral, tecnicista e 
conservadora como fundamento da ética docente, ainda que fosse oficial.

\section{REFERÊNCIAS}

ARENDT, H. Origens do Totalitarismo. São Paulo: Companhia das Letras, 2012.

EAGLETON, T. Ideologia - uma introdução. São Paulo: Editora da Universidade Estadual Paulista; Editora Boitempo, 1997.

ESCOLA SEM PARTIDO. Apresentação. São Paulo, 2014a. Disponível em: $<$ http://escolasempartido.org/off-textos-base/>. Acesso em: 18 set. 2020.

Objetivos. São Paulo, 2014c. Disponível em: <http://escolasempartido.org/blog/objetivos/>. Acesso em: 18 set. 2020.

FAQ. São Paulo, 2014e. Disponível em: <http://escolasempartido.org/blog/faq/>. Acesso em: 18 set. 2020.

FREIRE, P. Pedagogia do Oprimido. Rio de Janeiro: Paz e Terra, 1987.

GADAMER, H. Verdade e Método I: traços fundamentais de uma hermenêutica filosófica. Petrópolis: Vozes, 2013.

Verdade e Método II: complementos e índice. Petrópolis: Vozes, 2011.

GALILEI, G. Carta de Galileu a Francesco Ingoli. Scientiae Studia, São Paulo, v.3, n.3, p.477-516, 2005.

LÖWY, M. Ideologias e Ciência Social: elementos para uma análise marxista. São Paulo, 1991.

LUCKESI, C. Filosofia da educação. São Paulo: Cortez, 2011.

SAVIANI, D. Educação Brasileira: estrutura e sistema. Campinas, SP: Autores Associados, 1996.

SAVIANI, D. Escola e democracia. Campinas, SP: Autores Associados, 2008.

SEVERINO, A. Educação e ética no processo de construção da cidadania. In: LOMBARDI, J. C.; GOERGEN, P. (Orgs.). Ética e Educação: reflexões filosóficas e históricas. Campinas, SP: Autores Associados, 2005.

Recebido em: 28 abr. 2020.

Aceito em: 05 out. 2020. 